\title{
Rate of Compliance with Hand Hygiene by Dental Healthcare Personnel (DHCP) within a Dentistry Healthcare First Aid Facility
}

\author{
Marcília Batista de Amorim-Finzia \\ Mauro Vieira Cezar Cury \\ Cláudio Rodrigues R. Costab \\ Angelis Costa dos Santos ${ }^{b}$ \\ Geraldo Batista de Meloc
}

\section{ABSTRACT}

Objectives: To evaluate the compliance with the opportunities of hand hygiene by dentistry school healthcare professionals, as well as the higher choice products.

Methods: Through direct observation, the oral healthcare team-professors, oral and maxillofacial surgery residents, graduation students-for daily care were monitored: before performing the first treatment of the shift, after snacks and meals, and after going to the bathroom (initial opportunities) as well as between patients' care, and after ending the shift (following opportunities).

Results: The professors' category profited $78.4 \%$ of all opportunities while residents and graduation students did not reach $50.0 \%$ of compliance. Statistically significant data (P $\leq .05)$ were seen between categories: professors and residents, professors and graduation students, and between genders within the residents' category. When opportunities were profited, the preferred choice for hand hygiene was water and soap (82.2\%), followed by $70 \%$ alcohol (10.2\%), and both (7.6\%).

Conclusions: Although gloves were worn in all procedures, we concluded that the hygiene compliance by these professionals was under the expectation. (Eur J Dent 2010;4:233-237)

Key words: Hand hygiene; Dentistry school; Cross-transmission; Infection control.

- a MS, Department of Microbiology, Federal University of Uberlandia, Uberlandia-MG, Brazil.

b Federal University of Uberlandia, Faculty of Dentistry, Uberlandia-MG, Brazil.

PhD, Associate Professor, Department of Microbiology, Federal University of Uberlandia, Uberlandia-MG, Brazil.

- Corresponding author: Marcília Batista de Amorim-Finzi Federal University of Uberlandia, ICBIM, Department of Microbiology, Para Avenue, 1720 block 4C Campus Umuarama 38400-902. Uberlandia-MG, Brazil. Phone: +55 34 3218-2236 Fax: + 5534 3218-2333

E-mail: marthyamorimahotmail.com

\section{INTRODUCTION}

The hands of healthcare workers may serve a reservoir for pathogens, ${ }^{1,2}$ including those that are antibiotic multi-resistant and constantly associated with nosocomial infections. ${ }^{1}$ Effective hand hygiene practices are critical to preventing the transmission of healthcare-associated infections. ${ }^{3,4}$ Rates of healthcare-associated infection and the incidence of Methicillin-resistant Staphylococcus aureus (MRSA) are higher in the UK than in many other European countries. ${ }^{5}$ Many suc- 
cessful education programs in infection control have focused on hand hygiene $(\mathrm{HH}){ }^{6}$

The direct contact between healthcare professionals and patients is generally considered the first through which many exogenously acquired infections are spread inter- and intra-hospital facilities. ${ }^{7-9}$ The five components that should be included in multimodal strategies implemented to improve compliance and decrease the rate of cross-transmission and infection are as follows:

1. Monitoring practices and performance feedback.

2. Staff education.

3. Reminders in the workplace.

4. Adoption of an institutional safety climate.

5. Preferential recourse to the use of alcohol based hand rub instead of hand washing. ${ }^{10}$

In this sense, hand hygiene is thought to be the most important preventive measure, working as the main action to reduce those infections and cross-transmission of said pathogens, especially the multi-resistant ones, 8,9,11-15 including the oral healthcare setting. ${ }^{16}$

In medical teams, the low adherence to $\mathrm{HH}$ remains as a major issue in the healthcare context. Recent highlights on epidemiology suggest new approaches to health promotion monitoring $\mathrm{HH}^{8}$ that include direct observation, self-reporting by healthcare workers, measurement of $\mathrm{HH}$ product usage, and electronic methods. However, no ideal method of monitoring $\mathrm{HH}$ compliance has been developed. ${ }^{17}$ A clear understanding of the transmission process through the hands is crucial for success of the learning process. ${ }^{8}$

The patients and the dental healthcare personnel (DHCP) can be exposed to pathogenic microorganisms including cytomegalovirus (CMV), hepatitis B virus (HBV), hepatitis C virus (HCV), herpes simplex virus types 1 and 2, human immunodeficiency virus (HIV), Mycobacterium tuberculosis, staphylococci, streptococci, and other viruses and bacteria that colonize or infect the oral cavity and respiratory tract. ${ }^{18}$ These organisms can be transmitted in dental settings through: (1) direct contact with blood, oral fluids, or other patient materials; (2) indirect contact with contaminated objects such as instruments, equipment, or environmental surfaces; (3) contact of conjunctiva, nasal, or oral mucosa with droplets (e.g., spatter) containing microorganisms generated from an in- fected person and propelled a short distance le.g., by coughing, sneezing, or talking); and (4) inhalation of airborne microorganisms that can remain suspended in the air for long periods. ${ }^{18}$

It has been well documented that dental procedures can introduce oral pathogens into the bloodstream or lymphatic system via direct hematogenous spread or aspiration, thereby causing various medical conditions including bacteremia, aspiration pneumonia, coronary heart disease, preterm low birth weight, infective endocarditis, gastrointestinal infections, and osteogenic and prosthetic implant infections. ${ }^{19}$ In the present era of severe acute respiratory syndrome, avian flu, Influenza A (H1N1), and global problems with multiresistant pathogens, reliable information about these aspects is highly relevant. The importance of infection control in dentistry cannot be underestimated. ${ }^{20}$ There have been reports of potential cross-contamination with MRSA in dental clinics. ${ }^{21}$ It is essential to revise infection control measures in dental practices to accommodate these concerns. ${ }^{22}$ Because of the impossibility of identifying possible carriers of important pathogens such as HIV and HBV, among others, it is recommended that every patient, indiscriminately be considered as being potentially contaminated and that standardized protective measures be used before performing an invasive procedure. ${ }^{18}$

This work purpose was evaluating by the observational method the compliance of mouth health professionals with the hand hygiene good practices. With this type of study, the compliance rate with guidelines is evidenced, since the method may supply more accurate information.

\section{MATERIAL AND METHODS}

An observational, prospective, longitudinal study was carried out from January to December 2006 within the University hospital attached dental care unit first aid facility. Monitoring was done without the knowledge of the dental healthcare personnel, which included professors, residents, and graduation students of the University of the Dentistry School.

The groups were observed for hand cleaning before and after each clinical procedure that they executed during the workday. This study was not intended to assess the best way to clean their hands but to identify the preferred methods of 
hand cleaning and its adherence by dental healthcare personnel.

The treatment unit has four sinks for hand hygiene and four offices, each one with two dental care chairs outfitted with treatment equipment. The permanent staff is comprised of two professors and two residents (24-hour duty) and four to six graduation students (12-hour duty), all professionals undergoing shifts.

The statistical analysis was performed by the software GraphPhad Prism 5.0. The tests applied were: Chi-square $\left(X^{2}\right)$, Fisher's exact test for $n<5$, Mann-Whitney test, with $95 \%$ confidence interval, and ANOVA.

\section{RESULTS}

In our study, there were a total of 1,242 opportunities for hand hygiene by 225 individuals observed during the period from January to December 2006. Along the mouth healthcare performed by categories, compliance with hand hygiene was below the expectation (Table 1). Wearing of gloves occurred in all procedures within all categories.

The group of the residents reached $49.4 \%$ of compliance on the 190 opportunities observed. The professor's group of reached the highest compliance, $81 \%$ of the 361 opportunities of compliance (Table 1).

Graduation students constituted the greatest numbers of caregivers. Because they work more directly with the patients, they had the highest amount of opportunities at 691, and they reached $45 \%$ of compliance (Table 1 ).
In the initial opportunities-start of the shift, after snacks, meals and using the bathroom-an increased negligence was observed as compared with the subsequent opportunities such as between patients and at the end of the shift (Table 1).

Results were statistically significant when the groups were compared: professors versus residents opportunities (for hand hygiene adhered $(P<.05)$ and the choice of water and soap for hand hygiene $(P<.05))$; professors versus graduation students (opportunities not adhered $(P<.001)$ ), and residents versus graduation lopportunities for hand hygiene adhered $(P<.01)$ and not adhered $(P<.001)$; following opportunities adhered $(P<.05)$ and not adhered $(P<.05)$, and the choice of water and soap for hand hygiene $(P<.01)$ ) (Table 1).

For both residents and graduation students, the rate of compliance did not reach $50 \%$. The subgroup of females showed the lowest adherence among all the groups, highlighting the initial compliance of female residents, where compliance did not occur at all (Table 1).

In all the compliances observed in the study, the use of water and soap was the preferred method of hand hygiene (Figure 1). Hand friction with alcohol immediately after using water and soap was the less-applied technique, accounting for only $9 \%$ of the opportunities (Figure 1).

\section{DISCUSSION}

Hand hygiene is considered the single most effective method for preventing and controlling healthcare-associated infections. In the last few

Table 1. Rate of compliance with hand hygiene by dental healthcare personnel (total, initial and following opportunities) as well as the higher choice products.

\begin{tabular}{|c|c|c|c|c|c|c|c|c|c|}
\hline \multirow[b]{2}{*}{ Category (n) } & \multicolumn{2}{|c|}{ Opportunities \% (n) } & \multicolumn{2}{|c|}{ Initial \% (n) } & \multicolumn{2}{|c|}{ Following \% (n) } & \multicolumn{3}{|c|}{ Products \% (n) } \\
\hline & Adhered & $\begin{array}{c}\text { Not } \\
\text { adhered }\end{array}$ & Adhered & $\begin{array}{c}\text { Not } \\
\text { adhered }\end{array}$ & Adhered & $\begin{array}{c}\text { Not } \\
\text { adhered }\end{array}$ & $\begin{array}{l}\text { Water I } \\
\text { Soap* }\end{array}$ & Alcohol & Both \\
\hline Professors (43) & $78.4(283)$ & $21.6(78)$ & $62.3(43)$ & $37.7(26)$ & $82.2(240)$ & $17.8(52)$ & $73.2(276)$ & $14.3(54)$ & $12.5(47)$ \\
\hline Male (39) & 78.9 (265) & $21.1(71)$ & $63.7(42)$ & $33.3(22)$ & $82.0(223)$ & $18.0(49)$ & 72.3 (258) & $14.8(53)$ & $12.9(46)$ \\
\hline Female (4) & $72.0(18)$ & $28.0(7)$ & $20.0(1)$ & $80.0(4)$ & 85.0 (17) & $15.0(3)$ & $90.0(18)$ & $5.0(1)$ & $5.0(1)$ \\
\hline Residents (48) & 49.5 (94) & $50.5(96)$ & $31.0(18)$ & $69.0(40)$ & $57.6(76)$ & $42.4(56)$ & $81.2(82)$ & $14.8(15)$ & $4.0(4)$ \\
\hline Male (40) & $51.3(77)$ & 48.7 (73) & $37.5(18)$ & $62.5(30)$ & $58.0(59)$ & $42.0(43)$ & $77.4(65)$ & $17.8(15)$ & $4.8(4)$ \\
\hline Female (8) & $42.5(17)$ & $57.5(23)$ & $0.0(0)^{* *}$ & $100.0(10)$ & $56.7(17)$ & $43.3(13)$ & $100.0(17)$ & $0.0(0)$ & $0.0(0)$ \\
\hline Graduation (134) & $45.0(311)$ & $55.0(380)$ & $28.0(48)$ & $72.0(124)$ & 50.7 (263) & 49.3 (256) & 92.6 (313) & $4.1(14)$ & $3.3(11)$ \\
\hline Male (54) & $48.9(146)$ & 51.1 (153) & $31.4(22)$ & $68.6(48)$ & $54.1(124)$ & $45.9(105)$ & $92.6(148)$ & $3.7(6)$ & $3.7(6)$ \\
\hline Female (80) & $42.0(165)$ & $58.0(227)$ & $25.5(26)$ & $74.5(76)$ & 48.0 (139) & $52.0(151)$ & 92.7 (165) & $4.5(8)$ & $2.8(5)$ \\
\hline Total (225) & 55.3 (688) & $44.6(554)$ & 36.5 (109) & 63.5 (190) & $61.4(579)$ & 38.6 (364) & 82.2 (671) & 10.2 (83) & $7.6(62)$ \\
\hline
\end{tabular}

*: Not adhered to the first opportunity for hand hygiene. 
years, techniques for hand friction and drying have improved mainly through the use of alcohol-based solutions.

Although the group of professors reached $81 \%$ adherence to hand cleaning, the final result with the three studied groups presented inferior results $(55.4 \%)$ than those conducted in countries such as Canada and Italy (about 76.0\%). ${ }^{4}$

Another fact observed is that dental healthcare personnel have to travel large distances before arriving at the unit, and they handle several objects such as door handles and handrails. Some had possibly treated patients in another unit, which favors contamination and the transmission of microorganisms conveyed by their hands.

Direction campaigns should be stimulated to obtain a higher compliance with this basic routine for preventing infections related to healthcare; exclusively educational intervention proved insufficient in terms of respect compliance; moreover, highlighting the correct way of hand hygiene was not an aim of this study.

\section{CONCLUSIONS}

This study shows that most dental healthcare personnel wash their hands according to their needs, but they do not wash their hands according to the recommendations. Of the three groups observed, professors showed the highest compliance with rate of $78.4 \%$. Both residents and graduation students did not achieve $50 \%$ adherence, and

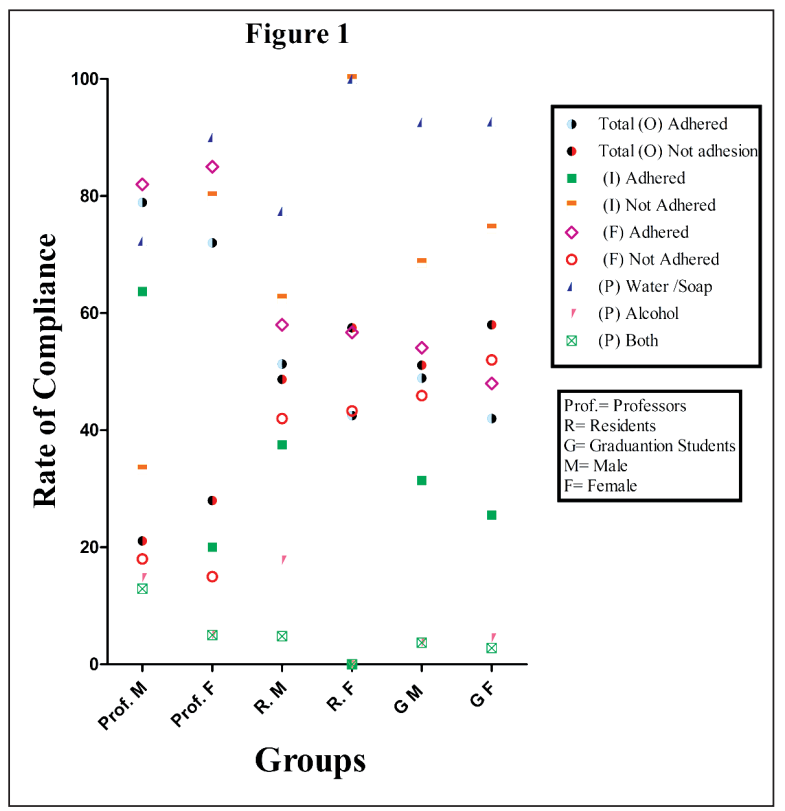

Figure 1. Comparison between the groups: opportunities (O); initial (I), following (F) of adherence, and products (P) of choice. the female subgroup of residents did not adhere even in initial opportunities.

Compliance programs developed should be implanted early in training and more frequently in the graduation and professional courses for dental healthcare personnel. The review of guidelines on hand hygiene, however, should be improved both for practices and standardization to help the projection of successful strategies for the intervention. Training campaigns and programs should be extended for each staff participant, especially these who develop activities with lower frequency within treatment units. More research is required to investigate problems associated with hand hygiene and to design interventions to improve compliance.

\section{REFERENCES}

1. Henderson DK. Managing methicillin-resistant staphylococci: A paradigm for preventing nosocomial transmission of resistant organisms. Am J Infect Control 2006;34:S46S54.

2. Cook HA, Cimiotti JP, Della-Latta P, Saiman L, Larson EL. Antimicriobial resistance patterns of colonizing flora on nurses' hands in the neonatal intensive care unit. Am J Infect Control 2007;35:231-236.

3. Braun BI, Kusek L, Larson E. Measuring adherence to hand hygiene guidelines: A field survey for examples of effective practices. Am J Infect Control 2009;37:282-288.

4. McCarthy GM, Koval JJ, MacDonald JK. Compliance with recommended infection control procedures among Canadian dentists: Results of a national survey. Am J Infect Control 1999;27:377-384.

5. Gould DJ, Hewitt-Taylor J, Drey NS, Gammon J, Chudleigh J, Weinberg JR. The CleanYourHandsCampaign: Critiquing policy and evidence base. J Hosp Infect 2007;65:95-101.

6. Farrington M. Infection control education: how to make an impact-tools for the job. J Hosp Infect 2007;65:128-132.

7. Beggs CB, Noakes CJ, Shepherd SJ, Kerr KG, Sleigh PA, Banfield $K$. The influence of nurse cohorting on hand hygiene effectiveness. Am J Infect Control 2006;34:621-626.

8. Pittet D, Allegranzi B, Sax H, Dharan S, Pessoa-Silva CL, Donaldson L, Boyce JM. Evidence-based model for hand transmission during patient care and the role of improved practices. Lancet Infect Dis 2006;641-652.

9. Stoner MJ, Cohen DM, Fernandez S, Bonsu BK. Physician handwashing: What do parents want? J Hosp Infect 2007;65:112-116. 
10. Pittet D. Hand hygiene: It's all about when and how. Infect Control Hosp Epidemiol 2008;29:957-959.

11. Sickbert-Bennett EE, Weber DJ, Gergen-Teague MF, Sobsey MD, Samsa GP, Rutala WA. Comparative efficacy of hand hygiene agents in the reduction of bacteria and viruses. Am J Infect Control 2005;33:67-77.

12. Randle J, Clarke M, Storr J. Hand hygiene compliance in healthcare workers. J Hosp Infect 2006;64:205-209.

13. Rutala WA, Morelli L, Weber DJ, Thomann CA. Effects of long-term storage on sterility of medical supplies. Am J Infect Control 2006;34: 248.

14. Whitby M, Pessoa-Silva CL, McLaws ML, Allegranzi B, Sax $H$, Larson E, Seto WH, Donaldson L, Pittet D. Behavioural considerations for hand hygiene practices: The basic building blocks. J Hosp Infect 2007;65:1-8.

15. Haas JP, Larson EL. Measurement of compliance with hand hygiene. J Hosp Infect 2007;66:6-14.

16. Huber MA, Holton RH, Terezhalmy GT. Cost analysis of hand hygiene using antimicrobial soap and water versus an alcohol-based hand rub. Oral Surg Oral Med Oral Pathol Oral Radiol Endod 2005;99:424.

17. Eveillard M, Hitoto $H$, Raymond F, Kouatchet A, Dube' L, Guilloteau V, Pradelle M-T, Brunel P, Mercat A, Joly-Guillou ML. Measurement and interpretation of hand hygiene compliance rates: Importance of monitoring entire care episodes. J Hosp Infect 2009; doi:10.1016/j.jhin.2009.03.025.

18. Kohn WG, Collins AS, Cleveland JL, Harte JA, Eklund KJ, Malvitz DM. Guidelines for infection control in dental health-care settings--2003. Centers for Disease Control and Prevention (CDC). MMWR Recomm Rep 2003;52:1-61.

19. Greco PM, Chern-Hsiung, L. A new method of assessing aerosolized bacteria generated during orthodontic debonding procedures. Am J Orthod Dentofacial Orthop 133:S79-S87.

20. Rautemaa R, Nordberg A, Wuolijoki-Saaristo K, Meurman $\mathrm{JH}$. Bacterial aerosols in dental practice-a potential hospital infection problem? J Hosp Infect 2006;64:76-81.

21. Kurita H, Kurashina K, Honda T. Nosocomial transmission of methicillin-resistant Staphylococcus aureus via the surfaces of the dental operatory. Br Dental J 2006;201:297300.

22. Al-Haroni M. Bacterial resistance and the dental professionals' role to halt the problem. J Dent 2008;36:95-103. 